\title{
Changes in the Antioxidant Properties of Quince Fruit (Cydonia oblonga Miller) during Jam Production at Industrial Scale
}

\author{
María V. Baroni $\mathbb{D}^{1,2,3}$ Joaquín Gastaminza, ${ }^{1,3}$ Natalia S. Podio, ${ }^{1,2}$ \\ Mariana S. Lingua, ${ }^{1}$ Daniel A. Wunderlin $\left(\mathbb{D},{ }^{1,2}\right.$ Jose L. Rovasio, ${ }^{4}$ Roberto Dotti, ${ }^{4}$ \\ Juan Carlos Rosso, ${ }^{4}$ Silvina Ghione, ${ }^{4}$ and Pablo D. Ribotta ${ }^{1,3,5}$ \\ ${ }^{1}$ Instituto de Ciencia y Tecnología de Alimentos Córdoba (ICYTAC), CONICET-UNC, Córdoba, Argentina \\ ${ }^{2}$ Departamento de Química Orgánica, Facultad de Ciencias Químicas, Universidad Nacional de Córdoba, Córdoba, Argentina \\ ${ }^{3}$ Instituto Superior de Investigación, Desarrollo y Servicios en Alimentos, SECYT, Universidad Nacional de Córdoba, \\ Córdoba, Argentina \\ ${ }^{4}$ Dulcor Alimentos, Arroyito, Cordoba, Argentina \\ ${ }^{5}$ Facultad de Ciencias Exactas Físicas y Naturales, Universidad Nacional de Córdoba, Córdoba, Argentina
}

Correspondence should be addressed to María V. Baroni; vbaroni@fcq.unc.edu.ar

Received 11 October 2017; Revised 25 January 2018; Accepted 13 February 2018; Published 20 March 2018

Academic Editor: Hüseyin Erten

Copyright (c) 2018 María V. Baroni et al. This is an open access article distributed under the Creative Commons Attribution License, which permits unrestricted use, distribution, and reproduction in any medium, provided the original work is properly cited.

\begin{abstract}
The content of phenolic compounds and their relationship with the antioxidant capacity of quince fruit were evaluated before and after jam processing at industrial scale. Waste samples from industrial processing were also analyzed. Twelve phenolics and one organic acid were identified and quantified by HPLC-DAD-QTOF. According to the results, jam processing did not produce a decrease in polyphenolic content, and, in some cases, the polyphenolic content even increased. Antioxidant capacities determined by DPPH and FRAP assays showed similar results. On the other hand, the waste samples analyzed retained large amounts of polyphenols, even though their antioxidant capacity was lower than that in pulp samples. Boosted Regression Trees analysis showed a good correlation between phenolic profile and antioxidant capacity, with 5 - $p$-coumaroylquinic acid being the most relevant compound to explain the antioxidant capacity by both methods.
\end{abstract}

\section{Introduction}

In recent years, it has become evident that significant health risks and benefits are associated with dietary food choices $[1$, 2]. Nutritional studies recommend the regular consumption of fruits and vegetables to favor a healthy quality of life [3].

Quince (Cydonia oblonga Mill.) belongs to the Maloideae subfamily of the Rosaceae family, which includes apples and pears, all of them commercially important fruits. Because of its hardness, acidity, and astringency, it is not edible without prior processing, but it is often used to prepare jam, jelly, liqueur, and marmalade, and it is applied in canning and for aromatic distillation $[4,5]$.

Several studies have shown that quince fruit is rich in polyphenols, organic acids, and amino acids with recognized beneficial effects on health $[1,6-8]$. Quince polyphenols are mainly hydroxycinnamic acids (caffeoyl and coumaroyl derivatives), flavonols (quercetin and kaempferol derivatives), and, in minor proportion, flavanols (catechin and epicatechin). In fact, quince is recognized as an important dietary source of compounds that promote health due to their antioxidant, antimicrobial, and antiulcerative action [9-12]. Furthermore, several studies have been published evaluating the effect of processing on the phenolic content and antioxidant capacity of quince fruit [1,13-15]. However, most of them evaluate the processing effects at a laboratory scale, not taking into account industrial processing. On the other hand, several reports describe polyphenolic content of peel and seeds obtained from quince fruits $[1,16]$.

In Argentina, unlike other countries such as Portugal, the whole fruit is crushed and heated and then the solids are separated according to different sieves. The pulp obtained is 
then mixed with sugars and additives to obtain quince jam. The discarded solid materials are composed of skin and seeds remnants and some mesocarp, too. It has been published that peel and seeds exhibit the highest content of polyphenols in the fruit $[1,8,15]$, so their characterization, from the antioxidant point of view, is important. Process sustainability is progressively becoming a mandatory standard, making the proposals for reusing or exploiting current industrial wastes relevant.

Nowadays, it is known that the antioxidant capacity (AC) cannot be easily predicted by the content of a specific group of compounds or by measuring a single substance [17, 18]. Besides, this capacity is the result of synergistic and antagonistic effects of the interactions of the different polyphenols between them and with other components of the food matrix or of the organism [19]. Therefore, we need to know the relative contribution of the entire phenolic profile on the $\mathrm{AC}$ of these exogenous natural antioxidants in order to explain their bioactive behavior. In this sense, BRT model (Boosted Regression Trees model) is a recent multivariate statistical technique that can be understood as an additive regression model used to explain and predict a response variable using several predictors. Among the advantages over traditional regression methods, we highlight the fact that the interactions among predictor variables are intrinsically detected in addition to the very complex and nonlinear association among variables identified [20-23].

The impact of food processing on polyphenols has been indicated not to be a simple cause-effect relationship [24]. Regarding the effect of thermal treatment on polyphenols, conflicting results have been reported. A positive effect has been observed for total phenolic content and antioxidant capacity in grape, orange juice and green tea, plum, black carrot jam and marmalade, and red beetroot jam [25-28], probably due to the disruption of the integrity of cell wall and membrane and because of the degradation of complexes formed with proteins [24]. Nevertheless, a negative effect has been observed in milk-based fruit beverages, pickled red beetroot, and plum and cabbage [27, 29, 30], possibly by the chemical degradation of these compounds due to the heat treatment.

Thus, the main goal of this study was to analyze the effects of industrial quince jam processing on the content of phenolic compounds and their relationship with the antioxidant capacity. In addition, it allowed characterizing Argentinean quince jam and waste from industrial processing, considering the phenolic profile and antioxidant capacity.

\section{Materials and Methods}

2.1. Chemicals. Methanol (HPLC grade) and formic acid (puriss. p.a. for mass spectroscopy) were obtained from J. T. Baker (Edo. de México, México) and Fluka (Steinheim, Germany), respectively. Commercial standards of $(+)$ catechin, caffeic acid, coumaric acid, and quinic acid were obtained from Extrasynthese (Genay, France). Kaempferol, 5-O-caffeoylquinic acid, and quercetin were purchased from Fluka (Dorset, UK). DPPH (1,1-diphenyl-2-picrylhydrazyl radical), TPTZ (2,4,6-tripyridyl-S-triazine), and Trolox (6-hydroxy-2,5,7,8-tetramethylchroman-2-carboxylic acid) were purchased from Sigma-Aldrich (Buenos Aires, Argentina). All other reagents were of analytical grade.

2.2. Samples. All samples were provided by Dulcor S.A. Samples were taken at three different production days. Once the fruit arrived at the industrial plant, it was sorted, washed, and coarsely ground. Ground fruit was brought to boil in a steam kettle to reach $100^{\circ} \mathrm{C}$ to inactivate enzymes. The mixture was sieved by different sieves (perforation of sieves was $6 \mathrm{~mm}, 1.5 \mathrm{~mm}$, and $0.5 \mathrm{~mm}$ ) to separate the pulp from skin and seeds. After sieving, three pulp samples and three waste samples (waste 1 from sieve $1.5 \mathrm{~mm}$ and waste 2 from sieve $0.5 \mathrm{~mm}$, resp.) were taken. The pulp was concentrated in a two-effect evaporator $\left(40-60^{\circ} \mathrm{C}\right.$ first effect and $70-85^{\circ} \mathrm{C}$ second effect) to $32^{\circ}$ Brix. Finally, the concentrated pulp was heated in a heat exchanger (to $100^{\circ} \mathrm{C}$ ) and packed until the production of the jam. For jam production, sugar $(50: 50$ proportion) was added to the concentrated pulp; the $\mathrm{pH}$ was checked and adjusted if needed by addition of a few drops of $50 \%$ citric acid solution to a target $\mathrm{pH}$ of 3.0 to 3.2 . The mixture was boiled to a final concentration of 65 to $68^{\circ} \mathrm{Brix}$ (approximately 104 to $105^{\circ} \mathrm{C}$ final boiling point). The jam was hot-packed at $90^{\circ} \mathrm{C}$. Three jam samples were taken at the end of processing.

2.3. Sample Preparation. Extraction of phenolic compounds from samples was carried out as described by Karar et al. [31] with minor changes. Briefly, samples were lyophilized and their moisture was calculated by weight difference before and after freeze-drying. The moisture percentage $(\mathrm{g} \%)$ ranged from 54 to 56 for waste 1 , from 26 to 28 for waste 2 , from 80 to 84 for pulp, and from 20.5 to 24 for jam. After lyophilization, samples were frozen using liquid nitrogen and ground until obtaining a fine powder. A $1 \mathrm{~g}$ portion of the treated sample was extracted with $15 \mathrm{~mL}$ of acidified methanol $(0.1 \% \mathrm{HCl}$ $\mathrm{v} / \mathrm{v}$ ) in a blender ( $\mathrm{T} 18$ digital ULTRA-TURRAX, IKA Labortechnik, Germany). The obtained homogenate was incubated with agitation for $2 \mathrm{~h}$ at $4^{\circ} \mathrm{C}$ and then centrifuged at $3000 \times \mathrm{g}$ for $10 \mathrm{~min}$. The supernatant was separated and the solid pellet reextracted with $5 \mathrm{~mL}$ of acidified methanol as previously described. The combined extracts were filtered, fractionated in Eppendorf tubes, and stored at $-80^{\circ} \mathrm{C}$ until analysis. The extraction procedure was carried out in triplicate for each sample. These extracts were used for phenolic profile and antioxidant capacity determination.

2.4. Determination of Phenolic Profile. All samples were analyzed by HPLC-DAD-ESI-MS/MS, as described by Lingua et al. [18]. Compounds present in samples were identified according to their retention times, UV-vis spectra, highresolution MS, and MS/MS spectra, in comparison with pure compounds, when available, or in comparison with compounds reported in the literature [4]. MS analysis was used for quantification of compounds with specific external calibration plot, constructed by linear regression from available standards $((+)$-catechin, caffeic acid, coumaric acid, quinic acid, kaempferol, 5-O-caffeoylquinic acid, and quercetin). The calibration curves were prepared by appropriate 
TABLE 1: Polyphenols identified in quince samples.

\begin{tabular}{|c|c|c|c|c|c|c|c|}
\hline Number & $\begin{array}{c}\mathrm{RT} \\
(\mathrm{min}) \\
\end{array}$ & Compound & $\begin{array}{l}\text { Molec. } \\
\text { formula }\end{array}$ & $\begin{array}{c}{[\mathrm{M}-\mathrm{H}]^{-}(m / z)} \\
\exp \end{array}$ & Error (ppm) & $\operatorname{MS}^{2}(m / z)$ & $\lambda_{\max }(\mathrm{nm})$ \\
\hline (1) & 7.2 & Quinic acid & $\mathrm{C}_{7} \mathrm{H}_{11} \mathrm{O}_{6}$ & 191.0565 & -1.9 & 173 & 223 \\
\hline (2) & 11.0 & Procyanidin dimer & $\mathrm{C}_{30} \mathrm{H}_{25} \mathrm{O}_{12}$ & 577.1347 & 0.7 & $\begin{array}{c}289,425,407 \\
540\end{array}$ & 278 \\
\hline (3) & 11.7 & 4-O-Caffeoylquinic acid & $\mathrm{C}_{16} \mathrm{H}_{17} \mathrm{O}_{9}$ & 353.0887 & -2.5 & 191,179 & $228,292 \mathrm{sh}, 326$ \\
\hline (4) & 11.9 & $(+)$ Catechin $^{*}$ & $\mathrm{C}_{15} \mathrm{H}_{13} \mathrm{O}_{6}$ & 289.0727 & -3.4 & 245,205 & 281 \\
\hline (5) & 12.5 & 3-p-Coumaroylquinic acid & $\mathrm{C}_{16} \mathrm{H}_{17} \mathrm{O}_{8}$ & 337.0905 & 6.1 & 191,173 & \\
\hline (6) & 12.6 & 5-O-Caffeoylquinic acid* & $\mathrm{C}_{16} \mathrm{H}_{17} \mathrm{O}_{9}$ & 353.0887 & -2.6 & 191 & 230, 301sh, 326 \\
\hline (7) & 12.8 & (-) Epicatechin & $\mathrm{C}_{15} \mathrm{H}_{13} \mathrm{O}_{6}$ & 289.0707 & 3.6 & 245,203 & 281 \\
\hline (8) & 13.9 & 5-p-Coumaroylquinic acid & $\mathrm{C}_{16} \mathrm{H}_{17} \mathrm{O}_{8}$ & 337.0915 & 5.1 & 191 & \\
\hline (9) & 18.0 & Quercetin-3-O-rutinoside* & $\mathrm{C}_{27} \mathrm{H}_{29} \mathrm{O}_{16}$ & 609.1433 & 2.8 & 301 & \\
\hline (10) & 18.4 & Quercetin-3-O-glucoside* & $\mathrm{C}_{21} \mathrm{H}_{19} \mathrm{O}_{12}$ & 463.0837 & 7.7 & 301 & 354 \\
\hline (11) & 20.2 & Kaempferol hexoside & $\mathrm{C}_{21} \mathrm{H}_{19} \mathrm{O}_{11}$ & 447.0942 & -2.0 & 284,255 & 357 \\
\hline (12) & 21.0 & Kaempferol rutinoside & $\mathrm{C}_{27} \mathrm{H}_{29} \mathrm{O}_{15}$ & 593.1561 & $-7,3$ & 284 & \\
\hline (13) & 23.7 & Quercetin* $^{*}$ & $\mathrm{C}_{15} \mathrm{H}_{9} \mathrm{O}_{7}$ & 301.0360 & -2.2 & 179,151 & 370 \\
\hline
\end{tabular}

RT, retention time; $[\mathrm{M}-\mathrm{H}]^{-}(\mathrm{m} / \mathrm{z})$, negatively charged molecular ion; $\mathrm{MS}^{2}(\mathrm{~m} / z)$, daughter ions produced from $[\mathrm{M}-\mathrm{H}]^{-}$fragmentation; $\lambda_{\max }$, maximum absorbance for compound identification by UV-vis spectra; sh, shoulder. ${ }^{*}$ Compounds identified using corresponding standards. Other compounds are tentatively proposed on the basis of RT, accurate MS, and MS/MS according to data from the literature.

dilutions from stock solutions in methanol (concentration of $1000 \mathrm{mg} \mathrm{L}^{-1}$ ). When reference compounds were not available, a calibration curve from a structurally related compound was used. The limit of detection (LOD) and limit of quantification (LOQ) of the method used to quantify the phenolic compounds were experimentally evaluated considering a signal-to-noise ratios of 3 and 10 , respectively. The precision of the method was evaluated by calculating the coefficients of variation $(\mathrm{CV})$ from at least nine determinations covering the specified range for the procedure. LOQ ranged from 0.0013 to $0.0500 \mathrm{mg} \mathrm{L}^{-1}$. CV were below $13 \%$. After appropriate dilution, all samples under study and standard solutions were filtered $(0.45 \mu \mathrm{m})$ and injected in the HPLC-DAD-ESI-MS/ MS system. All injections were performed in duplicate.

2.5. Measurement of the Antioxidant Capacity (AC). The AC of samples was measured with ferric reducing antioxidant power (FRAP), and free radical scavenging activity (DPPH) assays. For all assays, results were obtained by interpolating the absorbance on a calibration plot, constructed by linear regression using Trolox (linear range between 0 and $0.02 \mathrm{mmol}$ Trolox $\mathrm{L}^{-1}$ ). Results are expressed in mmol Trolox equivalents per $100 \mathrm{~g}$ of fresh weight $(\mathrm{fw})$ sample. All samples were analyzed in duplicate.

2.5.1. Ferric Reducing Antioxidant Power (FRAP). FRAP assay was performed in accordance with Benzie and Strain [32]. Briefly, $100 \mu \mathrm{L}$ of the appropriately diluted sample was added to $3 \mathrm{~mL}$ of the FRAP reagent, measuring the absorbance at $593 \mathrm{~nm}$ after incubation at room temperature for 6 min in dark conditions.

2.5.2. Free Radical Scavenging Activity (DPPH). DPPH assay was performed in accordance with Villaño et al. [33]. Briefly,
$100 \mu \mathrm{L}$ of the appropriately diluted sample was added to $3 \mathrm{~mL}$ of $60 \mu \mathrm{M} \mathrm{DPPH}^{*}$ (dissolved in methanol), incubated for $15 \mathrm{~min}$ in dark conditions, and measured at $515 \mathrm{~nm}$.

2.6. Statistical Analysis. Data are expressed as mean \pm SD and analyzed using ANOVA test (Fisher's test was performed) with $p<0.05$.

Boosted Regression Trees (BRT) analysis was used to examine the relative contribution of each polyphenolic compound to the antioxidant capacity (DPPH and FRAP). The relative contribution is scaled such that the sum is 100 , and higher numbers correspond to a stronger influence on the in vitro antioxidant capacity. The partial dependence plots show the net effects of a polyphenolic compound on the antioxidant capacity tests, illustrating their association, while all other compounds have an average effect on the BRT model. BRT models were constructed in R (version 3.1.1) by using the gbm library [20]. Cross-validation was used in order to avoid model overfitting. CV correlation (the correlation between predicted and raw data) was used to evaluate model performance. CV correlations close to 1 indicate good model predictions [20].

\section{Results and Discussion}

3.1. Phenolic Composition of Quince Samples. Quince samples were analyzed by HPLC-DAD-MS/MS, and 12 phenolic compounds and one organic acid were identified according to their retention times, fragmentation patterns data (mass spectrometry), and UV-vis spectra data (Table 1) and quantified in all samples (Table 2). All of the identified compounds had been previously reported in quince fruit samples, and concentrations are similar to those previously published $[1$, $4,13,31]$. 
TABLE 2: Phenolic composition of different samples analyzed ( $\mathrm{mg} / 100 \mathrm{~g}$ fresh weight).

\begin{tabular}{lcccc}
\hline Compound & Waste 1 & Waste & Pulp & Jam \\
\hline Quinic acid & $3.23 \pm 0.39^{\mathrm{a}}$ & $2.76 \pm 0.25^{\mathrm{b}}$ & $3.57 \pm 0.18^{\mathrm{a}}$ & $2.81 \pm 0.11^{\mathrm{b}}$ \\
4-O-Caffeoylquinic acid & $6.8 \pm 0.1^{\mathrm{a}}$ & $5.76 \pm 0.61^{\mathrm{b}}$ & $3.01 \pm 0.39^{\mathrm{c}}$ & $1.28 \pm 0.53^{\mathrm{d}}$ \\
3- -Coumaroylquinic acid & $0.160 \pm 0.010^{\mathrm{b}}$ & $0.100 \pm 0.010^{\mathrm{c}}$ & $0.440 \pm 0.020^{\mathrm{a}}$ & $0.080 \pm 0.020^{\mathrm{c}}$ \\
5-O-Caffeoylquinic acid & $15.85 \pm 2.42^{\mathrm{a}}$ & $14.65 \pm 2.62^{\mathrm{a}}$ & $12.83 \pm 1.47^{\mathrm{b}}$ & $10.58 \pm 0.92^{\mathrm{c}}$ \\
5- -Coumaroylquinic acid & $1.42 \pm 0.07^{\mathrm{b}}$ & $1.14 \pm 0.1^{\mathrm{c}}$ & $2.27 \pm 0.25^{\mathrm{a}}$ & $1.42 \pm 0.05^{\mathrm{b}}$ \\
$\sum$ Hydroxycinnamic acids & $27.47 \pm 2.70^{\mathrm{a}}$ & $24.4 \pm 3.52^{\mathrm{a}}$ & $22.12 \pm 1.85^{\mathrm{b}}$ & $16.17 \pm 0.49^{\mathrm{c}}$ \\
\hline Procyanidin dimer & $0.060 \pm 0.010^{\mathrm{a}}$ & $0.030 \pm 0.002^{\mathrm{b}}$ & $0.010 \pm 0.001^{\mathrm{c}}$ & $0.010 \pm 0.002^{\mathrm{c}}$ \\
(+) Catechin & $<\mathrm{LOD}^{\mathrm{a}}$ & $<\mathrm{LOD}$ & $0.060 \pm 0.010^{\mathrm{b}}$ & $0.030 \pm 0.010^{\mathrm{c}}$ \\
(-) Epicatechin & $4.94 \pm 0.42^{\mathrm{a}}$ & $2.52 \pm 0.39^{\mathrm{b}}$ & $2.25 \pm 0.57^{\mathrm{b}}$ & $1.24 \pm 0.48^{\mathrm{c}}$ \\
$\sum$ Flavanols & $5.00 \pm 0.40^{\mathrm{a}}$ & $2.55 \pm 0.39^{\mathrm{b}}$ & $2.32 \pm 0.57^{\mathrm{b}}$ & $1.28 \pm 0.48^{\mathrm{c}}$ \\
\hline Quercetin-3-O-rutinoside & $29.63 \pm 7.89^{\mathrm{b}}$ & $38.86 \pm 7.78^{\mathrm{a}}$ & $5.64 \pm 0.18^{\mathrm{c}}$ & $4.71 \pm 0.86^{\mathrm{c}}$ \\
Quercetin-3-O-glucoside & $0.030 \pm 0.003^{\mathrm{b}}$ & $0.020 \pm 0.003^{\mathrm{c}}$ & $0.060 \pm 0.003^{\mathrm{a}}$ & $0.010 \pm 0.001^{\mathrm{d}}$ \\
Kaempferol hexoside & $0.28 \pm 0.01^{\mathrm{b}}$ & $0.240 \pm 0.020^{\mathrm{b}}$ & $0.380 \pm 0.050^{\mathrm{a}}$ & $0.060 \pm 0.020^{\mathrm{c}}$ \\
Kaempferol rutinoside & $0.040 \pm 0.003^{\mathrm{b}}$ & $0.040 \pm 0.004^{\mathrm{b}}$ & $0.080 \pm 0.020^{\mathrm{a}}$ & $0.010 \pm 0.001^{\mathrm{c}}$ \\
Quercetin & $0.001 \pm 0.0005^{\mathrm{c}}$ & $0.020 \pm 0.002^{\mathrm{c}}$ & $0.370 \pm 0.020^{\mathrm{a}}$ & $0.320 \pm 0.040^{\mathrm{b}}$ \\
$\sum$ Flavonols & $29.98 \pm 7.90^{\mathrm{a}}$ & $39.18 \pm 7.80^{\mathrm{a}}$ & $6.53 \pm 0.14^{\mathrm{b}}$ & $5.11 \pm 0.82^{\mathrm{c}}$ \\
\hline
\end{tabular}

Quantification: quinic acid as quinic acid and the rest of hydroxycinnamic acids as 5-O-caffeoylquinic acid; all flavanols as $(+)$ catechin; kaempferol derivates as kaempferol and quercetin and quercetin glucoside as quercetin; and quercetin rutinoside as quercetin rutinoside. Different letters indicate significant differences $(p<0.05)$. <LOD: less than detection limit.

One organic acid (quinic acid) and four hydroxycinnamic acids were detected: two derivates of caffeoylquinic acid and two derivates of coumaroylquinic acid. These acids represented more than $70 \%$ of total phenolics in pulp and jam samples; however, they represented only $40 \%$ in waste samples. 5-O-Caffeoylquinic acid was the phenolic acid detected in highest concentration in all samples.

Flavonols were present as a mixture of different aglycone and glycosylated quercetin and kaempferol. Five flavonols were detected, representing $20 \%$ of total phenolics in pulp and jam; however, they represented $50 \%$ in waste samples. In all cases, the quercetin rutinoside was the flavonol detected in highest concentration.

Flavanols detected were essentially catechins and procyanidins. These compounds represented between 5 and $8 \%$ of total phenolics in all samples, with (-) epicatechin being the most important one in all sample types.

Waste samples were principally characterized by flavonols, and these samples had the highest concentrations of polyphenols (Table 2). As stated before, waste samples are mainly composed of skin and seeds. Therefore, our results are in concordance with previously published works stating that quince skin is characterized by a higher concentration of polyphenols in comparison with pulp, and its phenolic composition is characterized by the presence of flavonols and flavanols $[1,9,16]$. In their composition, pulp and jam samples had some phenolics coming from the skin, since the complete quince fruit was used in this case. However, in these types of sample, where the major component is pulp, hydroxycinnamic acids are the compounds with highest concentration as shown in Table 2.

Food processing can produce quantitative and qualitative changes in the polyphenolic content $[18,24,34,35]$. During the processing of quince fruit (from pulp to jam), some differences can be observed in the polyphenolic profile (Table 2). As stated in Materials and Methods, pulp represented $60 \%$ of the final product, so we expected to have $60 \%$ of polyphenols coming from the pulp in the jam. However, as shown in Table 2, some compounds presented higher contents than expected. It has been previously reported that food processing, including heat treatment, can increase the content of bioactive compounds in the final products $[36,37]$. An increase in polyphenolic content could be attributed to a disruption of plant cell walls, providing better extractability, breaking chemical bonds of higher molecular weight polyphenols, and forming soluble low molecular weight polyphenols and their interconversion $[1,36,37]$. For example, the highest concentration observed for quinic acid (18\% higher than expected) could be due to the hydrolysis of its derivates (3-p-coumaroylquinic acid). Quercetin-3-Orutinoside was found in a higher concentration than expected in jam, probably due to its liberation from cell structures of the peel during processing. On the other hand, the highest concentration of 5-O-caffeoylquinic acid observed in jam samples (22\% higher than expected) could be due to the interconversion with 4-O-caffeoylquinic acid [1]. It is worth mentioning that polyphenols resist technological conditions $\left(100^{\circ} \mathrm{C}\right)$ applied during jam production.

3.2. In Vitro Antioxidant Capacity (AC). The in vitro antioxidant capacity of quince samples was determined by the DPPH and FRAP methods. Results are shown in Figure 1.

As expected, jam samples presented lower values than pulp samples in the DPPH assay. DPPH values for pulp were $2166 \pm 156 \mu \mathrm{M}$ Trolox $/ 100 \mathrm{~g}$ fw, and for jam they were $1325 \pm$ $156 \mu \mathrm{M}$ trolox $/ 100 \mathrm{~g} \mathrm{fw}$, approximately $60 \%$ of pulp capacity, which is consistent with the percentage of pulp in the final product. On the other hand, DPPH values for waste samples 


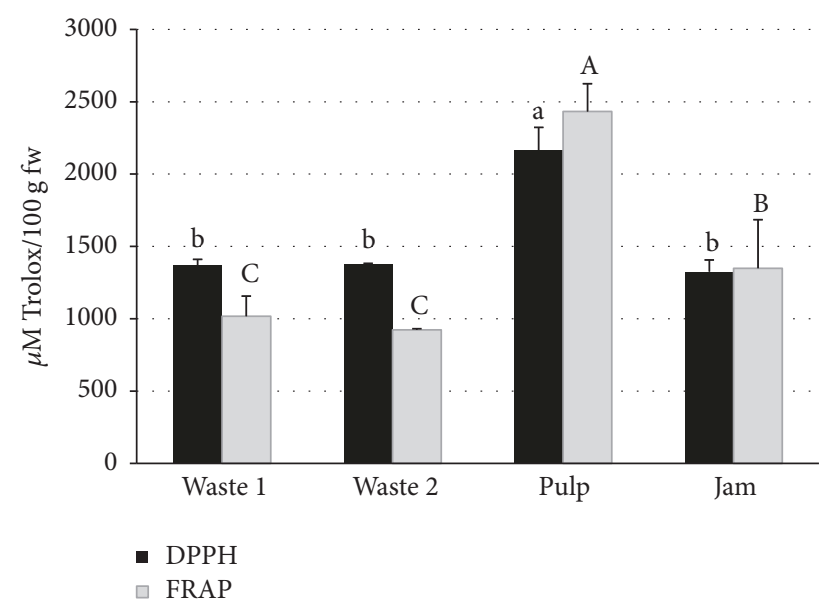

Figure 1: Antioxidant capacity ( $\mu$ mol equiv. Trolox/100g fresh weight). Different letters indicate significant differences within a method $(p<0.05)$.

(1 and 2) (1367 \pm 43 and $1374 \pm 8.3 \mu \mathrm{M}$ Trolox/100 g fw, resp.) were similar to jam samples.

FRAP results showed a similar trend with DPPH values. Pulp samples presented FRAP values of $2433 \pm 191 \mu \mathrm{M}$ Trolox $/ 100 \mathrm{~g} \mathrm{fw}$, and jam samples presented FRAP values of $1349 \pm 335 \mu \mathrm{M}$ Trolox/100 g fw, representing $60 \%$ of pulp capacity. In this case, waste samples (1 and 2) presented slightly lower values than jam samples $(1017 \pm 138$ and $923 \pm$ $8.04 \mu \mathrm{M}$ Trolox $/ 100 \mathrm{~g} \mathrm{fw}$, resp.) (Figure 1).

Taking into account the DPPH and FRAP results, we could say that quince processing did not affect $\mathrm{AC}$, as it was $60 \%$ of the starting material.

Some extra analyses of antioxidant activity of sugar solutions and mixtures of sugar and quince pulp prepared at the laboratory were performed (results not shown). No effects of sugar addition were observed on AC in this study. These results are in agreement with those obtained by Pengseng et al. [38] who observed that the addition of sucrose did not affect the antioxidant properties of p-hydroxycinnamic acids and of Tom-Kha paste extract; however, sugar changed the antioxidant activity of gallic acid, suggesting that the action of sucrose depends on the matrix phenolic profile.

Many works studied the changes on polyphenolic compounds caused by quince fruit processing or analyzed $\mathrm{AC}$ in fruit, peel, and jam [1], but these authors correlate the AC with the phenolic content found in jam, not comparing the AC with the starting material (pulp or pulp + peel), so they do not evaluate the effect of processing on AC. On the contrary, it has been observed that, for other fruits (black carrot, Vaccinium arctostaphylos, and cherry), jam manufacturing affects both polyphenolic content and AC $[26,39,40]$. This does not agree with our current results and previously published reports for quince jam $[1,15]$.

On the other hand, waste samples had similar AC values to jam samples, although waste samples presented the highest polyphenolic content (Table 2). In this sense, previous reports highlight the lack of correlation between total polyphenolic content and AC [1, 4]. Silva et al. [1] found that pulp and peel AC correlate with polyphenolic content, but in the case of quince seed, no correlation was observed. The authors indicate that these differences could be due to differences in the polyphenolic profile, but no further research on that was conducted. On the other hand, Fattouch et al. [9] found that the antioxidant capacity of quince pulp and peel showed stronger antioxidant effects compared to the sum of all individual pure compounds used at concentrations normally present in whole extracts. Therefore, it is important to consider the phenolic profile altogether in order to study the interactions between different antioxidant components, which are probably important in terms of the overall $\mathrm{AC}$ of the extracts.

3.3. Relationship between Polyphenolic Profile and In Vitro AC. In this work, we propose the use of BRT analysis to explore the relationship between phenolic profile and AC. This statistical technique enables us to evaluate the contribution of individual polyphenols to the AC, looking for evidence on different contributions of individual polyphenolic compounds to the AC. BRT identifies main predictor compounds, modeling complex functions (antioxidant capacity), without making assumptions about the type of data. BRT is robust to missing data, variable outliers, and variable collinearity, focusing on predictive accuracy rather than $p$ values to indicate the significance of model coefficients; that is why it is better than other multivariate techniques [21]. The adjusted parameters (bag fraction, learning rate, and tree complexity), performance ( $\mathrm{CV}$ correlation and number of trees), and relative influence of polyphenols for each model are presented in Table 3. BRT models showed a good performance (CV correlation: 1 ) in DPPH as well as FRAP analyses (Table 3). BRT model showed that nearly $90 \%$ of the variability found in DPPH analyses could be explained using 6 (relative influence in bold, Table 3) out of 13 quantified compounds. On the other hand, for the FRAP assay, 9 (relative influence in bold, Table 3) out of 13 quantified compounds are necessary to explain $90 \%$ of the variability observed. 5-p-Coumaroylquinic acid was the most significant compound for both antioxidant assays with a relative contribution of $25.7 \%$ to DPPH and $28.9 \%$ to FRAP assays. Additionally, other compounds were also important for both assays (quinic acid, 3-p-coumaroylquinic acid, 5-Ocaffeoylquinic acid, and kaempferol hexoside). On the other hand, some compounds were important predictor variables depending on each assay. Thus, kaempferol rutinoside was important for the DPPH BRT model, and procyanidin dimer, 4-O-caffeoylquinic acid, $(+)$ catechin, and quercetin-3-Orutinoside were important compounds for the FRAP model. The antioxidant techniques analyzed in this work evaluate different mechanisms of action of the polyphenols (free radical scavenging and reducing power), so these last polyphenols appear to be the most relevant to explain the $\mathrm{AC}$ according to the mechanism of action, while compounds in common to both BRT models could be considered important to explain the total AC [21, 22].

The partial dependence plots show the relationship of each polyphenolic compound at different concentrations with the DPPH or FRAP results (fitted function), while all other compounds have an average effect on the model [21]. Figure 2 provides the partial dependence plots of selected 

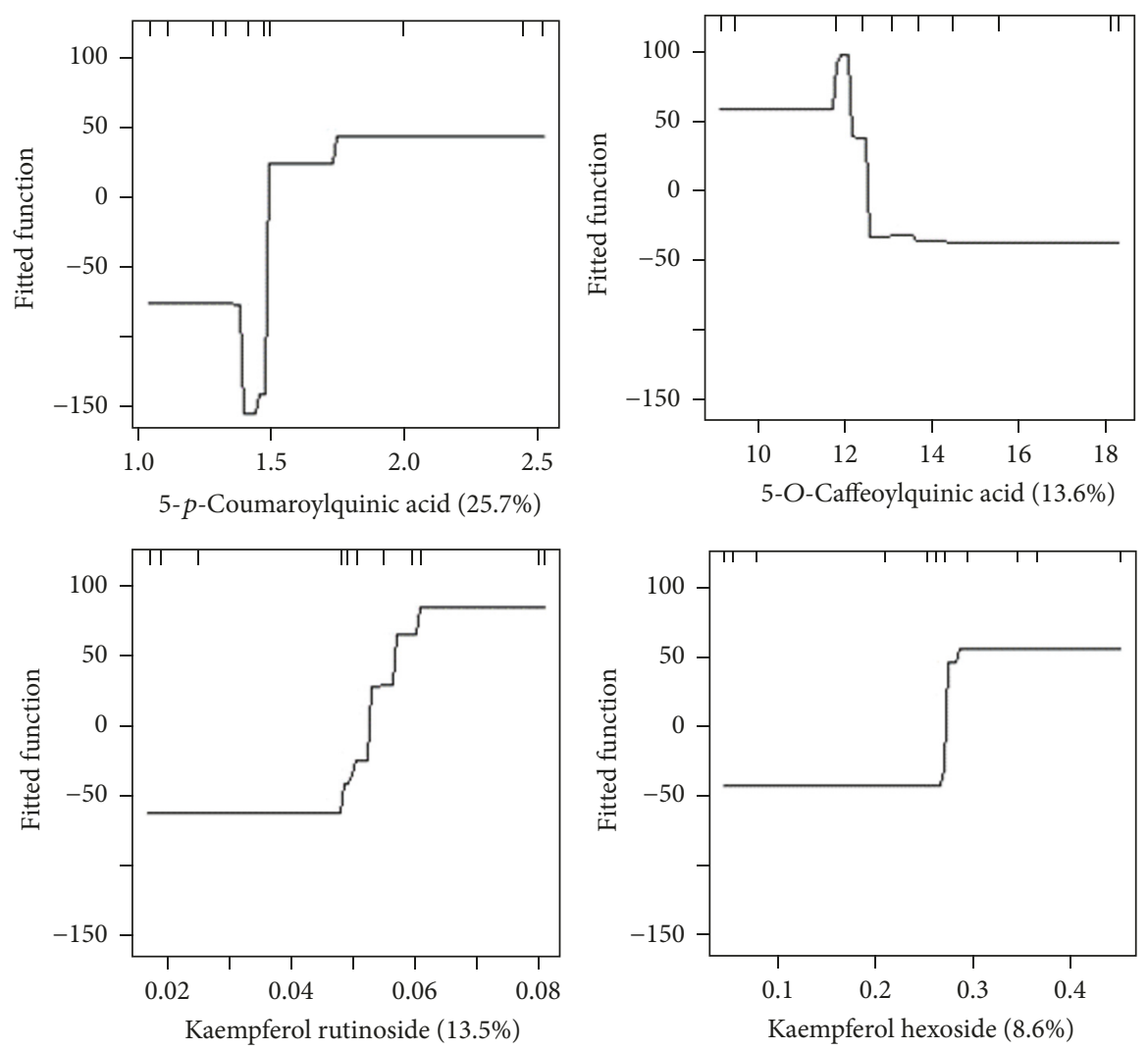

(a)
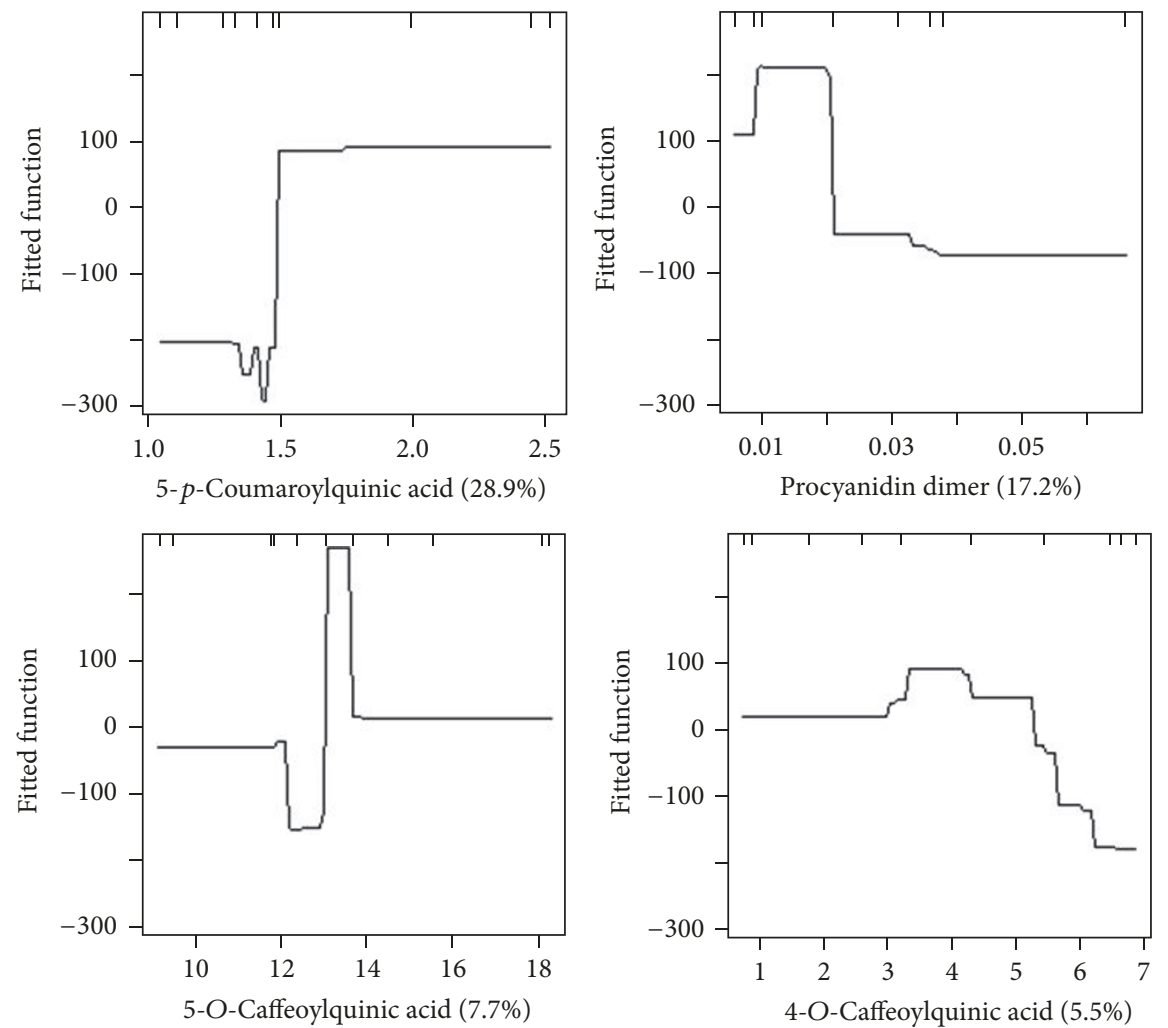

(b)

Figure 2: Functions fitted for the Boosted Regression Trees (BRT) model, showing the influence of selected polyphenols (mg/100 g) and their contribution (between square brackets) to fit the DPPH (a) and FRAP (b) BRT models. 
TABLE 3: Adjusted parameters, performance, and relative influence (\%) of Boosted Regression Trees models for antioxidant capacity (FRAP and DPPH) of quince samples.

\begin{tabular}{lcc}
\hline & DPPH & FRAP \\
\hline Adjusted parameters & 0.6 & \\
Bag fraction & 0.01 & 0.55 \\
Learning rate & 2 & 0.01 \\
Tree complexity & & 2 \\
\hline Model performance & 1 & \\
CV correlation & 31250 & 1 \\
Optimal numbers of trees & & 38000 \\
\hline Relative influence of polyphenols (\%) & $\mathbf{1 6 . 1}$ & \\
Quinic acid & 2.5 & $\mathbf{1 4 . 3}$ \\
Procyanidin dimer & 1.4 & $\mathbf{1 7 . 2}$ \\
4-O-Caffeoylquinic acid & 0.7 & $\mathbf{5 . 5}$ \\
(+) Catechin & $\mathbf{1 1 . 4}$ & 5.0 \\
3-p-Coumaroylquinic acid & $\mathbf{1 3 . 6}$ & $\mathbf{5 . 5}$ \\
\hline 5-O-Caffeoylquinic acid & 2.9 & $\mathbf{7 . 7}$ \\
(-) Epicatechin & $\mathbf{2 5 . 7}$ & 0.5 \\
5-p-Coumaroylquinic acid & 0.4 & $\mathbf{2 8 . 9}$ \\
\hline Quercetin-3-O-rutinoside & 3.3 & $\mathbf{4 . 9}$ \\
Quercetin-3-O-glucoside & $\mathbf{8 . 6}$ & 0.3 \\
Kaempferol hexoside & $\mathbf{1 3 . 5}$ & $\mathbf{4 . 6}$ \\
Kaempferol rutinoside & 0 & 4.1 \\
Quercetin & $\mathbf{1 0 0}$ & 1.6 \\
\hline Cumulative influence (\%) & & $\mathbf{1 0 0}$ \\
\hline
\end{tabular}

polyphenols on the DPPH (a) and FRAP (b) BRT models. For the DPPH BRT model, it can be observed that when the concentration of 5-p-coumaroylquinic acid is higher than $1.5 \mathrm{mg} / 100 \mathrm{~g}$, the concentration of kaempferol rutinoside is higher than $0.05 \mathrm{mg} / 100 \mathrm{~g}$, and the concentration of kaempferol hexoside is higher than $0.28 \mathrm{mg} / 100 \mathrm{~g}$; the free radical scavenging power is the highest. This is in concordance with the content of these compounds in the different samples, since these compounds presented the highest concentrations in pulp and jam samples. On the other hand, as it can be seen in Figure 2(a), concentrations of 5$O$-caffeoylquinic acid lower than $12 \mathrm{mg} / 100 \mathrm{~g}$ correspond to higher AC. In this sense, waste samples presented the highest concentration of these compounds.

Figure 2(b) shows the contribution of selected compounds to the FRAP BRT model. Higher reducing power is associated with concentrations of 5-p-coumaroylquinic acid higher than $1.5 \mathrm{mg} / 100 \mathrm{~g}$. In contrast, a concentration higher than $0.02 \mathrm{mg} / 100 \mathrm{~g}$ for procyanidin dimer and higher than $4 \mathrm{mg} / 100 \mathrm{~g}$ for 4 -O-caffeoylquinic acid shows lowest AC by the FRAP assay. This is in agreement with the concentrations found for these polyphenols in the different sample types. 5$O$-Caffeoylquinic acid shows a complex relationship between its content and $\mathrm{AC}$, as it is lower in a small range of concentrations (between 12 and $13 \mathrm{mg} / 100 \mathrm{~g}$ ), which is in concordance with its concentration in waste samples.

Taking into account these results, there is a complex pattern of variation between polyphenols' concentrations and antioxidant capacity (DPPH and FRAP). Low antioxidant capacity of waste samples with highest phenolic content could be explained by the polyphenolic profile determined.

\section{Conclusions}

The novelty of this paper is based on the fact that the samples were analyzed at industrial scale and on the use of Boosted Regression Trees analysis to study the contribution of polyphenols to the antioxidant capacity.

Industrial jam processing does not diminish the antioxidant quality of quince fruit. Processing qualitatively and quantitatively alters the phenolic profile, since some hydrolysis from large molecules and isomerization is produced, even though the antioxidant capacity is maintained. Additionally, the BRT method is a useful analytical tool to study the contribution of polyphenols to the antioxidant capacity. The results shown in this work demonstrate that the antioxidant capacity of quince samples, before and after jam processing, can be explained by the polyphenolic profile, with 5- $p$ coumaroylquinic acid being the most relevant compound to antioxidant capacity by the DPPH and FRAP methods. On the other hand, waste samples retain large amounts of phenolics and their antioxidant capacity is similar to jam. Therefore, the recovery of this waste as a source of natural antioxidants constitutes a major challenge.

\section{Conflicts of Interest}

The authors declare that they have no conflicts of interest.

\section{Acknowledgments}

The authors acknowledge grants from ANPCyT (PICT 20080554) and SECyT-UNC (Res. 162/12 and 203/14). They acknowledge Dulcor Alimentos for providing samples and support.

\section{References}

[1] B. M. Silva, P. B. Andrade, P. Valentao, F. Ferreres, R. M. Seabra, and M. A. Ferreira, "Quince (Cydonia oblonga Miller) fruit (pulp, peel, and seed) and Jam: antioxidant activity," Journal of Agricultural and Food Chemistry, vol. 52, no. 15, pp. 4705-4712, 2004.

[2] R. E. C. Wildman, "Nutraceuticals: a brief review of historical and teleological aspects," in Handbook of Nutraceuticals and Functional Foods, R. E. C. Wildman, Ed., pp. 1-12, CRC Press, Boca Raton, Fla, USA, 2001.

[3] O. Paredes-Lopez, M. L. Cervantes-Ceja, M. Vigna-Perez, and T. Hernández-Pérez, "Berries: improving human health and healthy aging, and promoting quality life-a review," Plant Foods for Human Nutrition, vol. 65, no. 3, pp. 299-308, 2010.

[4] A. Wojdyło, J. Oszmiański, and P. Bielicki, "Polyphenolic composition, antioxidant activity, and polyphenol oxidase (PPO) activity of quince (Cydonia oblonga Miller) varieties," Journal of Agricultural and Food Chemistry, vol. 61, no. 11, pp. 2762-2772, 2013. 
[5] C. A. Torres, L. A. Romero, and R. I. Diaz, "Quality and sensory attributes of apple and quince leathers made without preservatives and with enhanced antioxidant activity," LWT-Food Science and Technology, vol. 62, no. 2, pp. 996-1003, 2015.

[6] C. Kaur and H. C. Kapoor, "Antioxidants in fruits and vegetables. The millennium's health," International Journal of Food Science and Technology, vol. 36, no. 7, pp. 703-725, 2001.

[7] U. M. Acuna, D. E. Atha, J. Ma, M. H. Nee, and E. J. Kennelly, "Antioxidant capacities of ten edible North American plants," Phytotherapy Research, vol. 16, no. 1, pp. 63-65, 2002.

[8] B. M. Silva, P. B. Andrade, F. Ferreres, A. L. Domingues, R. M. Seabra, and M. A. Ferreira, "Phenolic profile of quince fruit (Cydonia oblonga Miller) (pulp and peel)," Journal of Agricultural and Food Chemistry, vol. 50, no. 16, pp. 4615-4618, 2002.

[9] S. Fattouch, P. Caboni, V. Coroneo et al., "Antimicrobial activity of tunisian quince (Cydonia oblonga Miller) pulp and peel polyphenols extracts," Journal of Agricultural and Food Chemistry, vol. 55, no. 3, pp. 963-969, 2007.

[10] Y. Hamauzu, H. Yasui, T. Inno, C. Kume, and M. Omanyuda, "Phenolic profile, antioxidant property, and anti-influenza viral activity of Chinese quince (Pseudocydonia sinensis Schneid.), quince (Cydonia oblonga Mill.), and apple (Malus domestica Mill.) fruits," Journal of Agricultural and Food Chemistry, vol. 53, no. 4, pp. 928-934, 2005.

[11] Y. Hamauzu, T. Inno, C. Kume, M. Irie, and K. Hiramatsu, "Antioxidant and antiulcerative properties of phenolics from Chinese quince, quince, and apple fruits," Journal of Agricultural and Food Chemistry, vol. 54, no. 3, pp. 765-772, 2006.

[12] Y. Hamauzu, T. Inno, C. Kume, M. Irie, K. Hiramatsu, and H. Yasui, "Some health beneficial properties of phenolics from Chinese quince, quince and apple," Acta Horticulturae, vol. 744, pp. 417-424, 2007.

[13] B. M. Silva, P. B. Andrade, P. Valentão, G. C. Mendes, R. M. Seabra, and M. A. Ferreira, "Phenolic profile in the evaluation of commercial quince jellies authenticity," Food Chemistry, vol. 71, no. 2, pp. 281-285, 2000.

[14] B. M. Silva, P. B. Andrade, G. C. Mendes, P. Valentão, R. M. Seabra, and M. A. Ferreira, "Analysis of phenolic compounds in the evaluation of commercial quince jam authenticity," Journal of Agricultural and Food Chemistry, vol. 48, no. 7, pp. 2853-2857, 2000.

[15] B. M. Silva, P. B. Andrade, A. C. Gonçalves, R. M. Seabra, M. B. Oliveira, and M. A. Ferreira, "Influence of jam processing upon the contents of phenolics, organic acids and free amino acids in quince fruit (Cydonia oblonga Miller)," European Food Research and Technology, vol. 218, no. 4, pp. 385-389, 2004.

[16] A. S. Magalhães, B. M. Silva, J. A. Pereira, P. B. Andrade, P. Valentão, and M. Carvalho, "Protective effect of quince (Cydonia oblonga Miller) fruit against oxidative hemolysis of human erythrocytes," Food and Chemical Toxicology, vol. 47, no. 6, pp. 1372-1377, 2009.

[17] M. V. Baroni, R. D. Di Paola Naranjo, C. García-Ferreyra, S. Otaiza, and D. A. Wunderlin, "How good antioxidant is the red wine? Comparison of some in vitro and in vivo methods to assess the antioxidant capacity of Argentinean red wines," LWT_Food Science and Technology, vol. 47, no. 1, pp. 1-7, 2012.

[18] M. S. Lingua, M. P. Fabani, D. A. Wunderlin, and M. V. Baroni, "From grape to wine: Changes in phenolic composition and its influence on antioxidant activity," Food Chemistry, vol. 208, pp. 228-238, 2016.
[19] S. Rohn, H. M. Rawel, and J. Kroll, "Antioxidant activity of protein-bound quercetin," Journal of Agricultural and Food Chemistry, vol. 52, no. 15, pp. 4725-4729, 2004.

[20] J. Elith, J. R. Leathwick, and T. Hastie, "A working guide to boosted regression trees," Journal of Animal Ecology, vol. 77, no. 4, pp. 802-813, 2008.

[21] N. S. Podio, R. López-Froilán, E. Ramirez-Moreno et al., "Matching in vitro bioaccessibility of polyphenols and antioxidant capacity of soluble coffee by boosted regression trees," Journal of Agricultural and Food Chemistry, vol. 63, no. 43, pp. 9572-9582, 2015.

[22] N. S. Podio, M. V. Baroni, and D. A. Wunderlin, "Relation between polyphenol profile and antioxidant capacity of different Argentinean wheat varieties. A Boosted Regression Trees study," Food Chemistry, vol. 232, pp. 79-88, 2017.

[23] D. Saha, P. Alluri, and A. Gan, "Prioritizing Highway Safety Manual's crash prediction variables using boosted regression trees," Accident Analysis \& Prevention, vol. 79, pp. 133-144, 2015.

[24] A. Cilla, L. Bosch, R. Barberá, and A. Alegría, "Effect of processing on the bioaccessibility of bioactive compounds-a review focusing on carotenoids, minerals, ascorbic acid, tocopherols and polyphenols," Journal of Food Composition and Analysis, 2016.

[25] Z. He, Y. Tao, M. Zeng et al., "High pressure homogenization processing, thermal treatment and milk matrix affect in vitro bioaccessibility of phenolics in apple, grape and orange juice to different extents," Food Chemistry, vol. 200, pp. 107-116, 2016.

[26] S. Kamiloglu, A. A. Pasli, B. Ozcelik, J. Van Camp, and E. Capanoglu, "Colour retention, anthocyanin stability and antioxidant capacity in black carrot (Daucus carota) jams and marmalades: effect of processing, storage conditions and in vitro gastrointestinal digestion," Journal of Functional Foods, vol. 13, pp. 1-10, 2015.

[27] B. Guldiken, G. Toydemir, K. Nur Memis, S. Okur, D. Boyacioglu, and E. Capanoglu, "Home-processed red beetroot (Beta vulgaris L.) products: changes in antioxidant properties and bioaccessibility," International Journal of Molecular Sciences, vol. 17, no. 6, article 858, 2016.

[28] N. Miletic, O. Mitrovic, B. Popovic, V. Nedovic, B. Zlatkovic, and M. Kandic, "Polyphenolic content and antioxidant capacity in fruits of plum (Prunus domestica L.) Cultivars 'Valjevka' and 'Mildora' as influenced by air drying,' Journal of Food Quality, vol. 36, no. 4, pp. 229-237, 2013.

[29] A. Cilla, A. Alegría, B. De Ancos et al., "Bioaccessibility of tocopherols, carotenoids, and ascorbic acid from milk- and soybased fruit beverages: Influence of food matrix and processing," Journal of Agricultural and Food Chemistry, vol. 60, no. 29, pp. 7282-7290, 2012.

[30] A. Kaulmann, C. M. André, Y.-J. Schneider, L. Hoffmann, and T. Bohn, "Carotenoid and polyphenol bioaccessibility and cellular uptake from plum and cabbage varieties," Food Chemistry, vol. 197, pp. 325-332, 2016.

[31] M. G. E. Karar, D. Pletzer, R. Jaiswal, H. Weingart, and N. Kuhnert, "Identification, characterization, isolation and activity against Escherichia coli of quince (Cydonia oblonga) fruit polyphenols," Food Research International, vol. 65, pp. 121-129, 2014.

[32] I. F. F. Benzie and J. J. Strain, "The ferric reducing ability of plasma (FRAP) as a measure of 'antioxidant power': the FRAP assay," Analytical Biochemistry, vol. 239, no. 1, pp. 70-76, 1996.

[33] D. Villaño, M. S. Fernández-Pachón, A. M. Troncoso, and M. C. García-Parrilla, "Influence of enological practices on the 
antioxidant activity of wines," Food Chemistry, vol. 95, no. 3, pp. 394-404, 2006.

[34] D. T. Tembo, M. J. Holmes, and L. J. Marshall, "Effect of thermal treatment and storage on bioactive compounds, organic acids and antioxidant activity of baobab fruit (Adansonia digitata) pulp from Malawi," Journal of Food Composition and Analysis, vol. 58, pp. 40-51, 2017.

[35] M. Aguedo, S. Kohnen, N. Rabetafika et al., "Composition of by-products from cooked fruit processing and potential use in food products," Journal of Food Composition and Analysis, vol. 27, no. 1, pp. 61-69, 2012.

[36] J. Lachman, K. Hamouz, M. Orsák et al., "Impact of selected factors-Cultivar, storage, cooking and baking on the content of anthocyanins in coloured-flesh potatoes," Food Chemistry, vol. 133, no. 4, pp. 1107-1116, 2012.

[37] C. Fares, C. Platani, A. Baiano, and V. Menga, "Effect of processing and cooking on phenolic acid profile and antioxidant capacity of durum wheat pasta enriched with debranning fractions of wheat," Food Chemistry, vol. 119, no. 3, pp. 1023-1029, 2010.

[38] N. Pengseng, S. Siripongvutikorn, W. Usawakesmanee, and S. Wattanachant, "Combined effect of carbohydrate and thermal processing on antioxidant activity of galangal coconut-milk paste extract, Tom-Kha," International Food Research Journal, vol. 18, no. 3, pp. 907-914, 2011.

[39] A. Güder, M. S. Engin, M. Yolcu, and M. Gür, "Effect of processing temperature on the chemical composition and antioxidant activity of vaccinium arctostaphylos fruit and their jam," Journal of Food Processing and Preservation, vol. 38, no. 4, pp. 1696-1704, 2014.

[40] T. M. Rababah, M. Al-U’Datt, M. Al-Mahasneh et al., "Effect of Jam processing and storage on phytochemicals and physiochemical properties of cherry at different temperatures," Journal of Food Processing and Preservation, vol. 38, no. 1, pp. 247-254, 2014. 


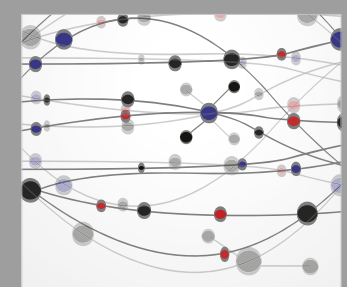

The Scientific World Journal
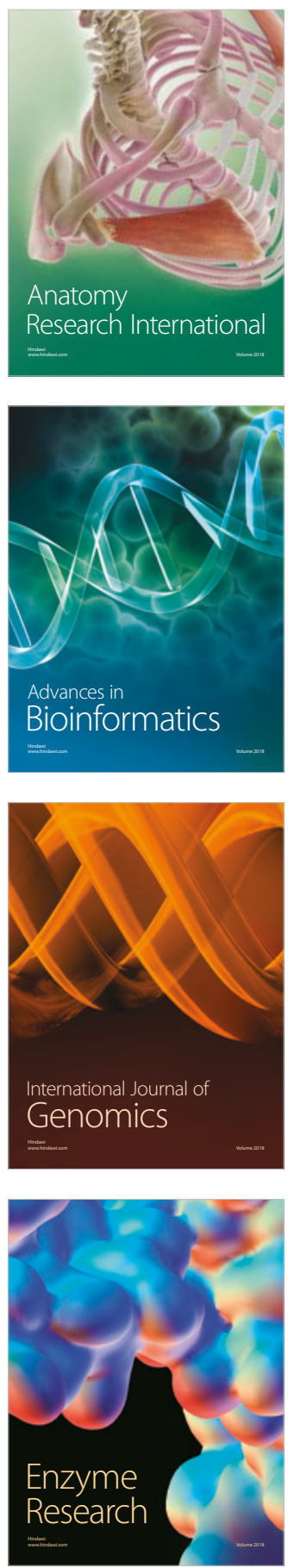
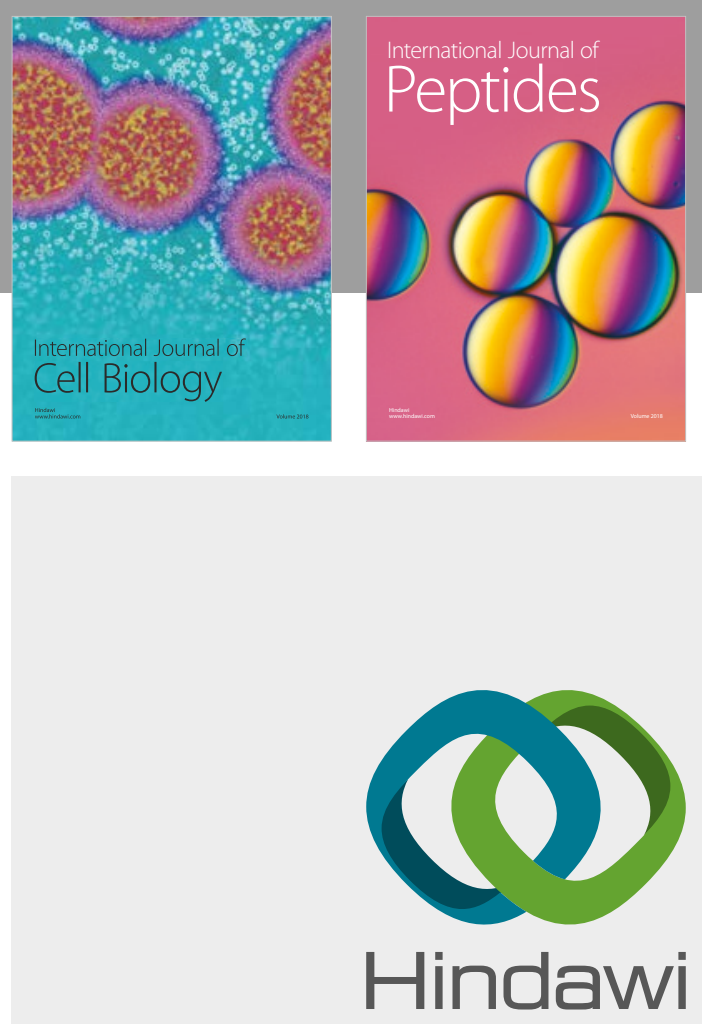

Submit your manuscripts at

www.hindawi.com
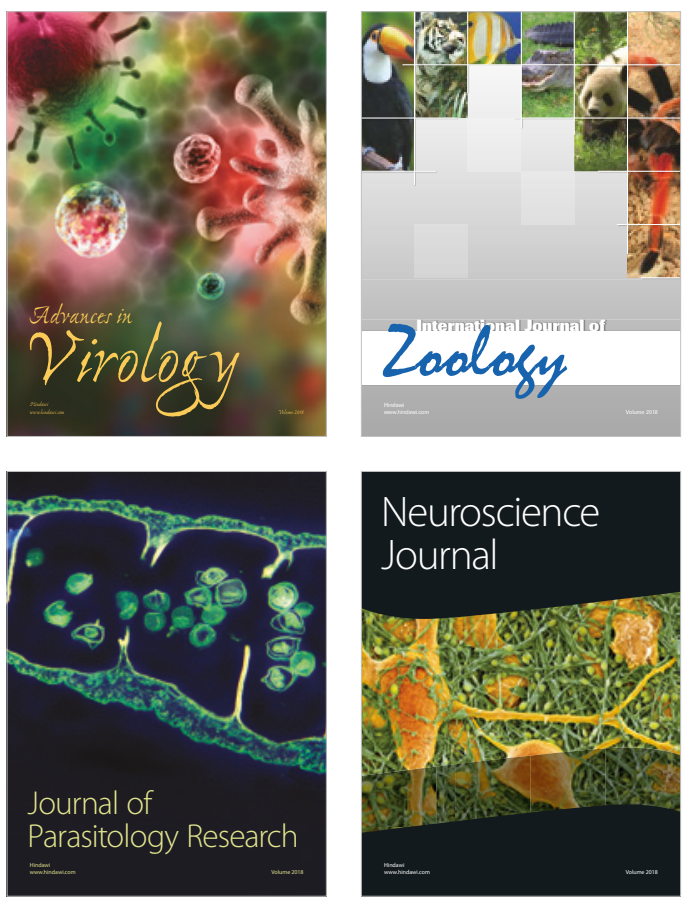
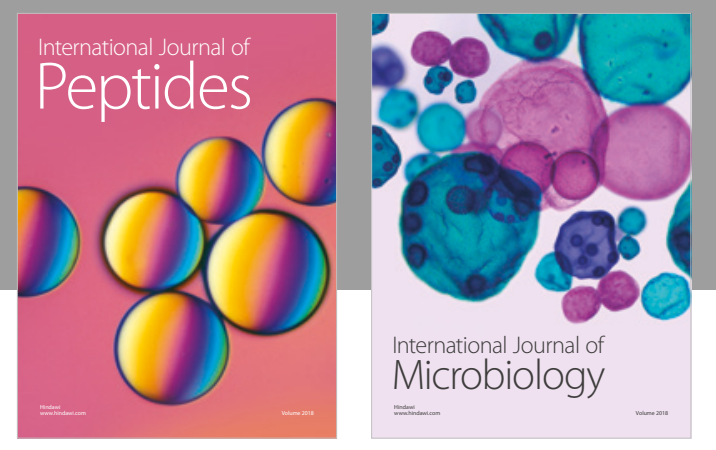

nternational Journal of Microbiology
Journal of
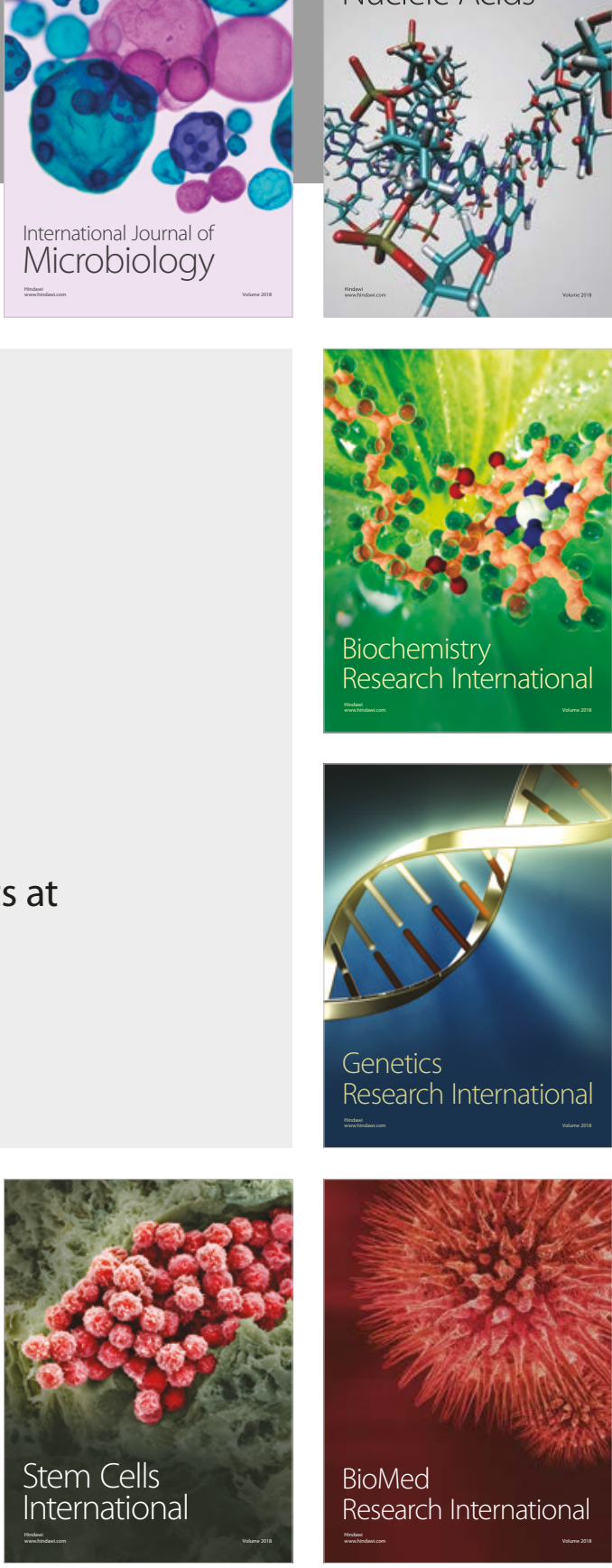
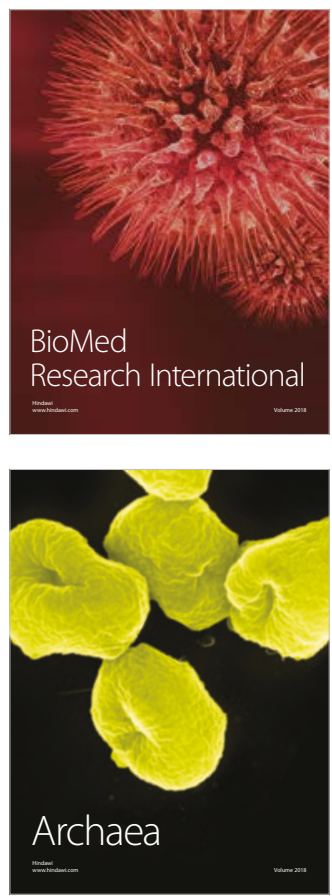